in the local condition for which the patient applied in the first place; but now that the ophthalmic benefit is beginning to be placed on a proper basis, it is probable that the panel doctor will make more effort to determine whether the patient's symptoms are or are not due to errors of refraction. The case of offenders in this respect will no doubt be investigated by the Ministry of Health, but we are not aware that any competent authority has been appointed by this body to investigate such cases.

There is another aspect of the ophthalmic benefit which has not yet been investigated and that is, what is to be done with the panel patients when they attend ophthalmic hospitals? Is it the duty of the hospital to refer these patients back to their panel practitioner for a recommendation to see an ophthalmic surgeon, or should they be treated at the hospital in the ordinary way?

In some instances patients bring their society's ophthalmic benefit letters to the hospital. The fees which are payable to an ophthalmic surgeon on the filling up of this letter are not payable to hospital authorities and the cases should be referred to an ophthalmic surgeon on the ophthalmic panel. Many of the letters issued by the approved societies have no place for the signature or certificate of an. ophthalmic surgeon, which is evidently a mistake on their part, as otherwise they do not know to whom the fee for examination should be paid. Sufficient time has not elapsed for the working of the benefit to settle down, but information on the points referred to above and others which may arise would be of considerable service in determining how the benefit is working all over the country.

We understand that a sub-committee has been appointed by the Council of British Ophthalmologists to inquire into the subject; information from our readers would be of considerable service and should be sent to the Hon. Secretary of the Council of British Ophthalmologists, 86, Brook Street, London, W.1.

\title{
DEPUTATION FROM THE JOINT COUNCIL OF QUALIFIED OPTICIANS AND THE BRITISH OPTICAL ASSOCIATION TO THE MINISTRY OF HEALTH
}

The Minister of Health, the Rt. Hon. Neville Chamberlain, received on March 26 a deputation from the Joint Council of Qualified Opticians, with which was associated the British Optical Association, to discuss a Bill to secure the registration of Optical Practitioners and to regulate the practice of sight testing and optical dispensing, which had been presented to Parliament by a Private Member. The deputation was introduced by Mr. S. P. Viant, M. P. 
Mr. Aves (Chairman of the Council of the Institute of Ophthalmic Opticians) said that the qualified opticians had been refused representation on the Departmental Committee on the causes and prevention of blindness; they had not been allowed to give evidence before the Committee; and representations which they had made after the Report of the Committee had been published by the Ministry of Health had not been fairly considered. Further, they had not been fully consulted before the scheme of optical treatment to be given as an additional benefit under the National Health Insurance Scheme had been drawn up. There had in the past been a conflict of views between the opticians and the doctors, but the opticians claimed that they were as fully alive to the needs of the public health as the doctors, and they had no desire but to arrive at some arrangement which would meet the legitimate objections that had been raised against the registration of opticians. The opticians only claimed competence to deal with errors of refraction and to detect functional abnormalities requiring specialist treatment by an ophthalmic surgeon, and it was a condition of the diplomas granted to opticians by their organizations that all cases of functional abnormalities should be referred to a medical practitioner. He claimed that they had therefore done all that the Minister--in speaking on Dr. Graham Little's Motion about the registration of osteopaths in the House of Commons-had advised osteopaths to do, before claiming the right to prohibit unregistered practice. They had already established a college, a hospital, and diplomas. He urged that a Committee should be appointed to decide whether the Government would not be well advised to accept the Bill promoted by the opticians.

Mr. Barker (President of the British Optical Association) said that the optical trade was united on the question. The treatment of errors of refraction was so important both to the industry and to the public that it should be under the sanction of the law and limited to those who had been educated to treat them and at the same time to detect functional abnormalities. The Royal Commission on National Health Insurance had been satisfied with the competence of the opticians to deal with errors of refraction, which, according to the evidence put forward by medical specialists, amounted to a very large percentage of the total cases of defective vision. Legislation similar to that which was proposed was already in force throughout practically the whole of the British Empire and the United States of America.. He claimed that the Bill would be of value to the community and a protection against charlatans, and would put an end to the conflict of views that had arisen between the opticians and the doctors.

Mr. Houghton (Chairman of the Joint Council of Qualified Opticians) said that for three years opticians had been treating 
insured persons to the perfect satisfaction of approved societies and to the insured population. There was little or no evidence of any serious consequences to any single patient through having been treated by an optician. Rather the case was that they could and in many cases did recognize disease, and in accordance with the condition of their diplomas referred the patients to qualified ophthalmic surgeons. The public resented the waste of time involved in having always to consult doctors before receiving ophthalmic benefit.

The Minister said that the Bill as drafted would debar doctors from treating defects of vision. This was perhaps not an insuperable difficulty, but he doubted whether any amendment which would remove it would leave the Bill in a form acceptable to the opticians. But the whole difficulty was that defect of vision might be due to simple errors of construction in the eye itself which can be corrected mechanically by glasses; to disease in the eye needing treatment apart from the provision of glasses, or disease not localized in the eye but due to a pathological condition in the body. If a case was not rightly classified serious injury to the patient might ensue. Even if such a risk were confined to a very small percentage of patients he would not be justified in submitting them to it, as he was advised that it was in fact very serious indeed. He was also not satisfied that the Optical Board proposed in the Schedule to their Bill was one which would secure the qualification only of persons competent to recognize disease, and he pointed out that 18 of the 25 members of the proposed Board were to be opticians.

It was not possible to argue from conditions in one country to those in another. Conditions in the Dominions were entirely different. There were vast territories with relatively small and widely-scattered populations who could not all be served by doctors. Nor could he accept their argument that his advice to the osteopaths supported their claim. After advising the osteopaths to set up a college and institute a diploma he had gone on to speak of the way in the United States of America the osteopaths had assimilated their curriculum to that of the medical schools. He did not see how the opticians could similarly assimilate their curriculum.

He admitted, however, they had a case up to a certain point. He had some sympathy with their claim that persons who had properly qualified themselves to treat errors of refraction not requiring medical attention should have a special label, and he would like to meet this point. The difficulty out of which he could not see his way was how patients suffering from simple errors of refraction could be distinguished from those in whom defect of vision was due to some pathological condition. 